\title{
Analysis of Mechanical Response of a Novel Adjustable Steel Arch
}

\author{
Wusi Chen ${ }^{1}$, Yonggao Tan², Peng Xiong ${ }^{2}$, Peng Duan ${ }^{1, *}$, Wang Yang ${ }^{2}$ and Jingyuan Wang² \\ ${ }^{1}$ Chongqing Jianzhu College, Chongqing 400072, China \\ ${ }^{2}$ Yichang Road Construction and Maintenance Center, Yichang 443000, China
}

Received 2 September 2019; Accepted 4 November 2019

\begin{abstract}
Steel arches are widely used to construct main arches in modern concrete bridges. However, the applicability of existing steel arches has certain limitations. To expand the application scope of steel arches and enhance the material utilization rate, this study proposed a calculation and analysis model for a novel steel arch with an adjustable axis. First, the finite element calculation model of the arch structure was established using the finite element software Midas Civil based on Timoshenko beam theory. Second, the sensitive factors that affect the mechanical response characteristics of the novel arch, such as the connection method of the upper chord in the arch section, boundary conditions of the arch springing hinge, and temperature, were thoroughly discussed through calculation and analysis of engineering projects. Finally, the effect of span and width on the arch stability was discussed using the linear elastic analysis method. The mechanical response of the new steel arch was obtained, and the reliability of the calculation results was verified. Results demonstrate that a rigid connection is applicable to the upper chord connection of the arch section, and the two-hinged arch applies to the frame. Temperature changes can lead to obvious deformation and the decrease in temperature indicates a clear stress on the arch. Without considering wind load, the minimum wide-span ratio for the novel arch reaches 1:20. This study can provide a reference for application and calculation analysis of such arches.
\end{abstract}

Keywords: Adjustable steel arch, Finite element, Mechanical response, Wide-span ratio

\section{Introduction}

Arch bridges, which have a long history, have been widely used in China's highway and railway networks. Engineers often use arch centering as the main arch in the construction of concrete bridges when encountering $\mathrm{V}$-shaped and $\mathrm{U}$ shaped steep valleys and valleys [1]. The arch centering can be classified into the Bailey-style assembled steel arches and the "64" assembled steel arches [2]. The former has advantages of light weight, simple components, and convenient disassembly. However, the arch axis is a broken line and cannot completely fit the axis of the main arch ring as a circular arc or catenary. Compared with the Bailey-style assembled steel arch, the "64" assembled steel arches have greater strength and applicability [3]. However, numerous varieties of chords increase the likelihood of assembly on different arch segments, causing material waste and prolonging the construction period [4]. With the advancement of steel and the manufacturing process, together with the continuous innovation and optimization of arch structures, a pioneering steel arch with adjustable axis made of high-performance steel has been developed in China. The most outstanding advantage of this arch is its adjustability, enhancing its applicability and material utilization rate. However, no systematic specification has been provided for the novel steel arch, bringing inconvenience to design and causing unnecessary losses to construction.

*E-mail address: ii_qiao@163.com

ISSN: 1791-2377 @ 2019 School of Science, IHU. All rights reserved.

doi:10.25103/jestr.126.05
At present, numerous studies on the mechanical response of arch centering [5-8] have achieved fruitful results. However, given the recent development of the novel steel arch with adjustable axis, study on its mechanical response mechanism is scarce. In engineering practices, no effective theoretical basis exists for mechanical response law and stability analysis of this novel steel arch

This study uses the finite element software Midas Civil to establish a finite element calculation model for the adjustable steel arch, and analyzes the sensitive factors that affect its mechanical response characteristics and stability. The aims are to clarify the mechanical response characteristics of the novel adjustable steel arch and provide reference for the application and computational analysis of such arches.

\section{State of the art}

The structure and construction of concrete arch bridges have been extensively studied worldwide. Zanardo [9] evaluated the static and seismic performance of a short-span concrete arch bridge before and after reinforcement, and discussed the influence of retrofit measures on structural safety and crosssectional thickness of arches. However, the study excluded a comprehensive evaluation of the stability of arch bridges. To determine the thermal performance of a concrete box arch bridge, Wang [10] calculated the thermal field using the two-dimensional planar finite element model on the basis of the meteorological parameter method. Similarly, the study evaluated the three-dimensional beam finite element model of thermal stress and displacement of arch bridges on the 
basis of vertical temperature gradient. However, the mechanical effects of shrinkage and creep on arch bridges were not considered. Elrehim [11] used the finite element numerical model to numerically simulate the arch bridge structure and optimize the design using the genetic algorithm developed by MATLAB programming platform. Although the construction costs were significantly decreased, compared with that of traditional design, the study did not conduct a nonlinear analysis of arch bridges. By establishing a finite element model of a nonlinear beam that considers concrete restraint and cracking, Dagher [12] evaluated the bending response of CFFT concrete arches. The model predicted load-deformation and moment-curvature behaviors that were in agreement with the measured data. However, the bending moment increase coefficient was not discussed. Hamed [13] carried out an experiment to discover the evolution of the behavior and failure mechanism of fiberreinforced polymer (FRP) medium and small concrete arch bridges. Nevertheless, the effect of structural size on reinforcement was neglected. Based on a comparative study of 55 concrete arch bridges built in the last century, Salonga [14] included cross-sectional dimensions and geometric bridge proportions into a database to identify empirical trends related to important properties such as stiffness, slenderness ratio, and efficiency. Furthermore, the study proposed a method to quantitatively characterize the aesthetics of concrete arch bridges. However, the selection of arch bridge structure and evaluation of several key mechanics problems were not involved. Khan [15] applied the displacement-based design method applicable for buildings and conventional bridges to reinforced concrete arch bridges and calculated the yield displacement and deformation capacity of the piers. However, the nonlinear analysis did not adequately verify the design results.

Steel arches likewise gained research attention. Jiang $\mathrm{Xu}$ [16] analyzed the "64" military beam steel arch in the Zhengzhou Bridge expansion project in Chongqing using finite element software and obtained the change law of its stability. The study reported that different casting schemes of the arch ring should be strictly calculated to ensure that the construction plan meets the requirements for stability. However, the influence of chord connection on the arch section on stability was not discussed. Tang Lifa [17] introduced four methods of bracket load test in detail and conducted a comparative analysis, finding that the mixing method had high safety factor, short test time, and low construction cost. Thrall [18] proposed a new adjustable steel structure module for steel plate bridge systems (like Bailey beam) to form a more effective variable depth arch bridge. The finite element analysis results showed that the module has advantages of light weight, reusability, and quick assembly compared with the existing system. Moreover, three-hinged and double-hinged arches with variable depths can be formed, and the material efficiency increases by approximately three times. However, the effect of wind load and temperature on the module was neglected. Based on the calculation and analysis of the strength, stiffness, and stability of the arch during the load test of a bridge by a finite element method, Jiang Tianyong [19] determined the reasonable pre-camber. The bearing capacity could meet the pouring of arch rib concrete, providing guidance for the pouring of the arch ring. However, the mechanical sensitivity factors of the arch were not analyzed. Zhang Yuping [20] studied the overall unloading method of steel arches, analyzed the force and deformation of the structure, and suggested that the arch foot falling from the arch simultaneously or successively has less influence on internal force or shape. However, the mechanical behavior of steel arches was not involved. Ma Feng [21] introduced new construction practices, checking calculation in design and construction points of a lightweight steel arch with integral traverse, adjustable span, and width for a cast-inplace monolithic reinforced concrete box arch bridge with a net span of $120 \mathrm{~m}$ in Guizhou, China. The study pointed out that constructing arch bridge with different spans and widths is applicable. However, the arch cannot adjust the axis. The Monte Carlo method based on response surface (MCS-RSM) was applied to reinforced concrete arch bridges with adjustable steel arches. Zhao Jingang [22] analyzed the randomness of the load ratio of steel arches and the dome deflection and studied the contribution of each random variable through a sensitivity analysis. The conclusions helped determine the steel arch assembly geometry, but did not discuss the stability of the arch. Zhao Wei [23] proposed to use large-span steel arch traverse construction technology for a double-arched arch bridge in Bijie, China to considerably reduce the construction costs and time period. However, the axis and the span of the arch cannot be adjusted.

In view of the deficiency of existing studies, the present study proposed a novel steel arch with an adjustable axis. Using the finite element software Midas Civil, a finite element calculation model of the arch structure was established based on Timoshenko beam theory. Moreover, the sensitive factors that affect the mechanical response characteristics of the novel arch, such as the connection factors of the upper chord on the arch section, boundary conditions of the arch hinge, and temperature, were analyzed through calculation of engineering examples. The influence of span and width on the arch stability was analyzed using the linear elastic analysis method. The results provide reference for the application and calculation analysis of such arches in the future.

The remainder of this study is organized as follows. Part 3 introduces the structure of the novel steel arch and constructs the finite element analysis model. Part 4 discusses the sensitive factors of the mechanical response characteristics of the new arch. The influence of span and width on the stability of the arch is analyzed based on the linear elastic theory. The last part summarizes the study and draws the conclusions.

\section{Methodology}

\subsection{Engineering background}

The novel arch frame with adjustable axis used in a rebuilt bridge in Yichang, China is considered as the engineering case background. The steel arch is a circular arc with a radius of $90.74 \mathrm{~m}$. The span of the two-hinge arch is $\mathrm{L}=86.11 \mathrm{~m}$, and the corresponding vector height is $\mathrm{f}=15.10$ $\mathrm{m}$. The arch is composed of a springer, standard, adjustment, and dome sections together with a coupling system and its connecting members. These sections and the coupling system are all-welded structures made of Q345B steel connected by screws, pins, and bolts. The cross-section of the arch comprises five basic sections and four coupling systems. Figure 1 shows the cross-section layout of the steel arch. 


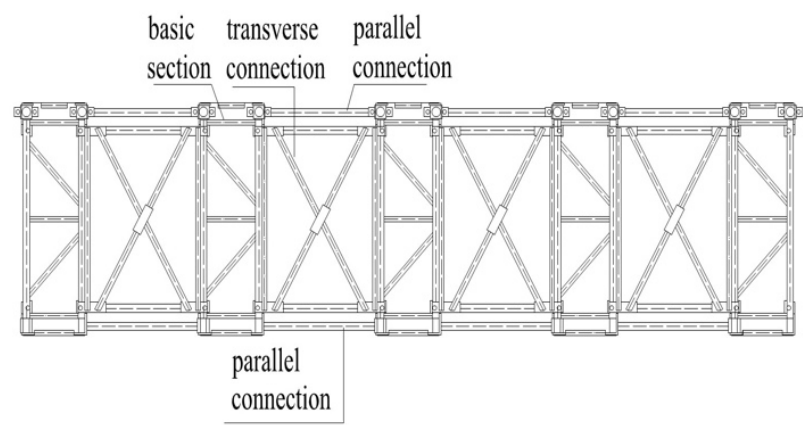

Fig. 1. Cross-section layout of steel arch

\subsection{Adjustable structure of the novel arch}

The adjustable structure of the novel arch with adjustable axis includes an adjustment section, a connecting member, and a coupling system. The adjustability of the novel arch mainly refers to the cast-in-place construction of the main arch ring of arch bridges applicable to varying spans, arch axle coefficients, and arch ring widths.

\subsubsection{Structure with adjustable span}

No special section is needed when the novel arch with adjustable axis is used to construct bridges with different spans and different arch axes. The concrete cast-in-place arch ring support is composed of the adjustment, section, and arch foot sections.

\subsubsection{Structure with adjustable width}

In the cast-in-place construction of the concrete arch ring, rings with different widths can be constructed by increasing the number of arches in the transverse bridge direction. The connection between the upper and lower chord planes in the basic segments of the novel arch with an adjustable axis is called parallel connection, while that between the basic segments in the vertical plane in the transverse direction a transverse connection.

\subsubsection{Structure with adjustable axis}

The two ends at the upper chord joint of the novel arch with adjustable axis are called plug and socket connectors of the adjusting screw. In arch assembly, the screw is rotated to satisfy the structural requirements of the axis. Figures 2 and 3 show the structures of the adjusting screw and the upper chord end respectively. The connecting bolts with diameter of $38 \mathrm{~mm}$ are arranged on the left and right sides (lateral) of the adjusting screw to reinforce the joint strength of the upper chord and position the segments. Figure 4 shows the section connection of the arch.

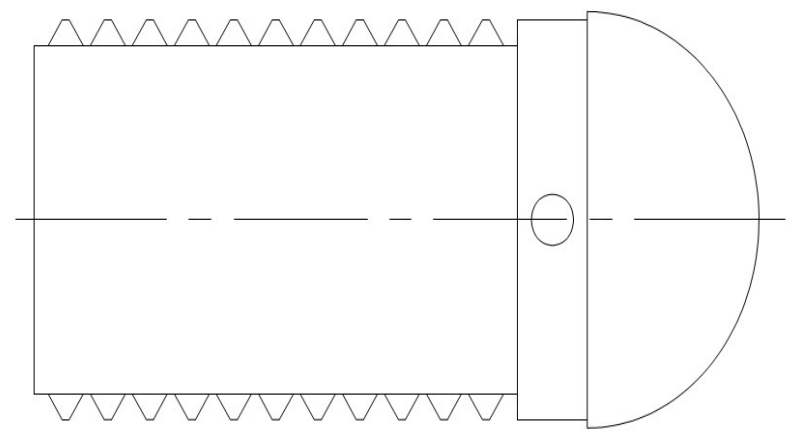

(a) Elevation structure of plug connector

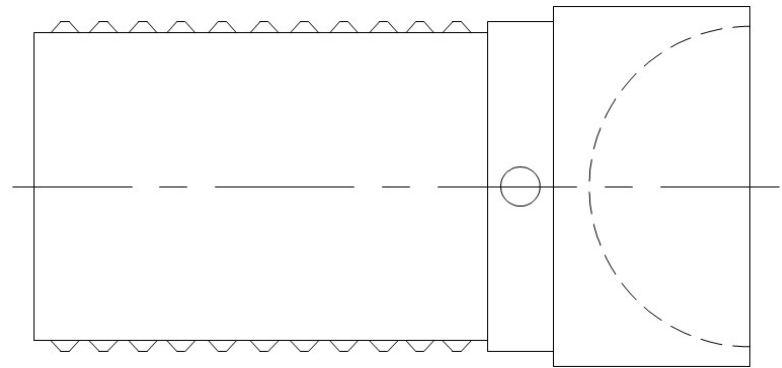

(b) Elevation structure of socket connector

Fig. 2. Structure of the adjusting bolt (unit: $\mathrm{mm}$ )

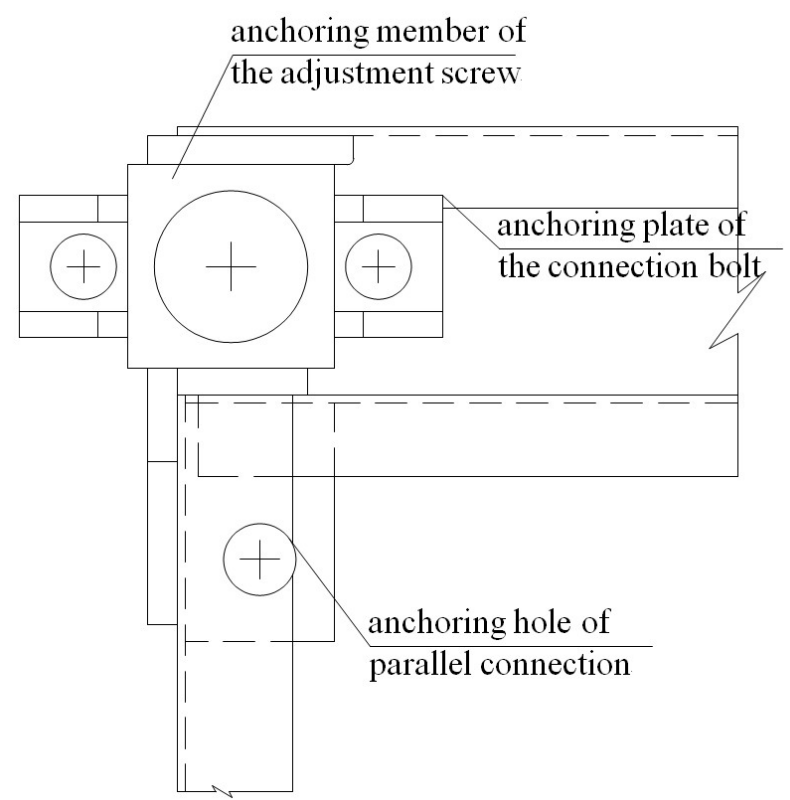

Fig. 3. Schematic diagram of the upper chord end (unit: mm)

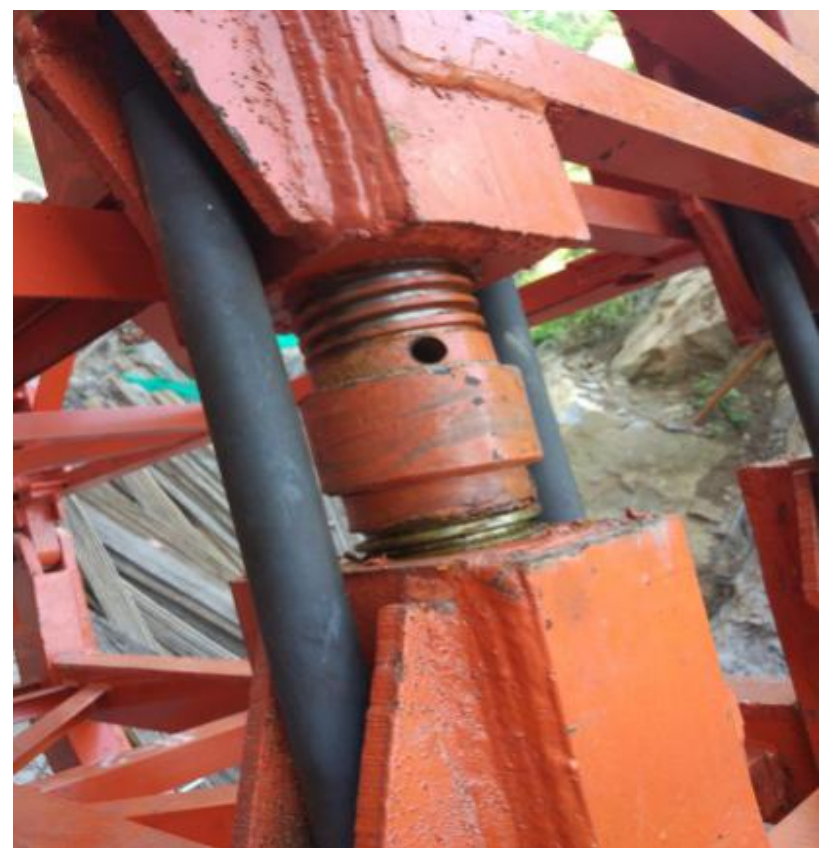

Fig. 4. Diagram of arch connection

\subsection{Linear elasticity analysis method}

To prevent the unstable equilibrium of the novel arch, evaluating its stability is necessary [24]. A reasonable evaluation method is defined, namely, qualification using the stability safety coefficient. In this study, the first type of 
stability analysis of steel arches is carried out, namely, linear elastic stability analysis (buckling analysis) [25]. The influence of the structure's geometry and the material nonlinearity is not considered in the linear elastic stability analysis of the novel arch. The basic calculation formula is as follows:

$$
\left([\mathrm{K}]+\lambda\left[\mathrm{K}_{\mathrm{d}}\right]\right)\{\delta\}=0
$$

Where $[\mathrm{K}]$ is the overall elastic stiffness matrix of the structure, $\left[\mathrm{K}_{\mathrm{d}}\right]$ is the overall geometric stiffness matrix of the structure, $\{\delta\}$ is the displacement matrix of the node, $\lambda$ is the stable safety coefficient.

\subsection{Finite element numerical simulation}

In this study, the three-dimensional finite element software Midas Civil is used to simulate the structure of the novel arch with adjustable axis. The upper and lower chords, webs, slanting rods, and coupling systems are simulated by the beam element. The bridge arch model is established based on the centroid position of each chord. The hinge between the lower chords of the arch is simulated using the beam-end release constraint.

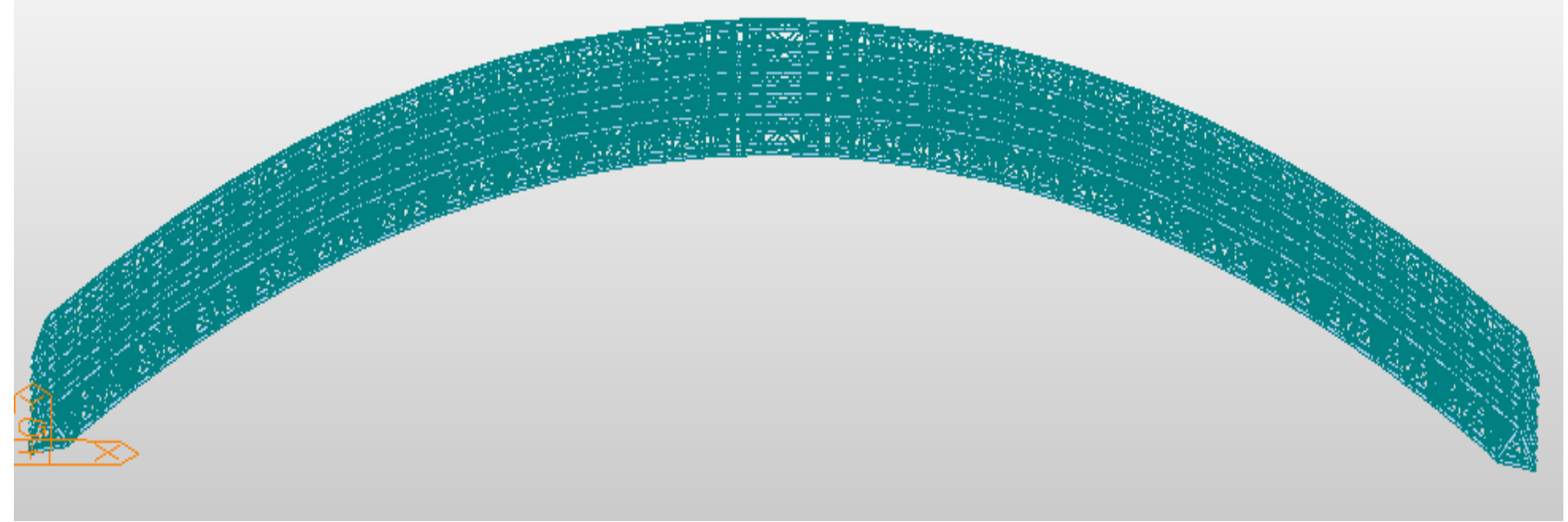

Fig. 5. Finite element model

On the basis of the main arch, the casting process of the arch rings is divided into 10 construction stages, numbered 1-10 from the arch, baseplate arch foot section, baseplate arch vault section, baseplate arch waist section, web arch foot section, web arch vault section, web arch waist section, crown plate arch foot section, crown plate arch vault section, to the crown plate arch waist section. The steel arch mainly bears the pressure and the nodal load transmitted by the main arch ring.

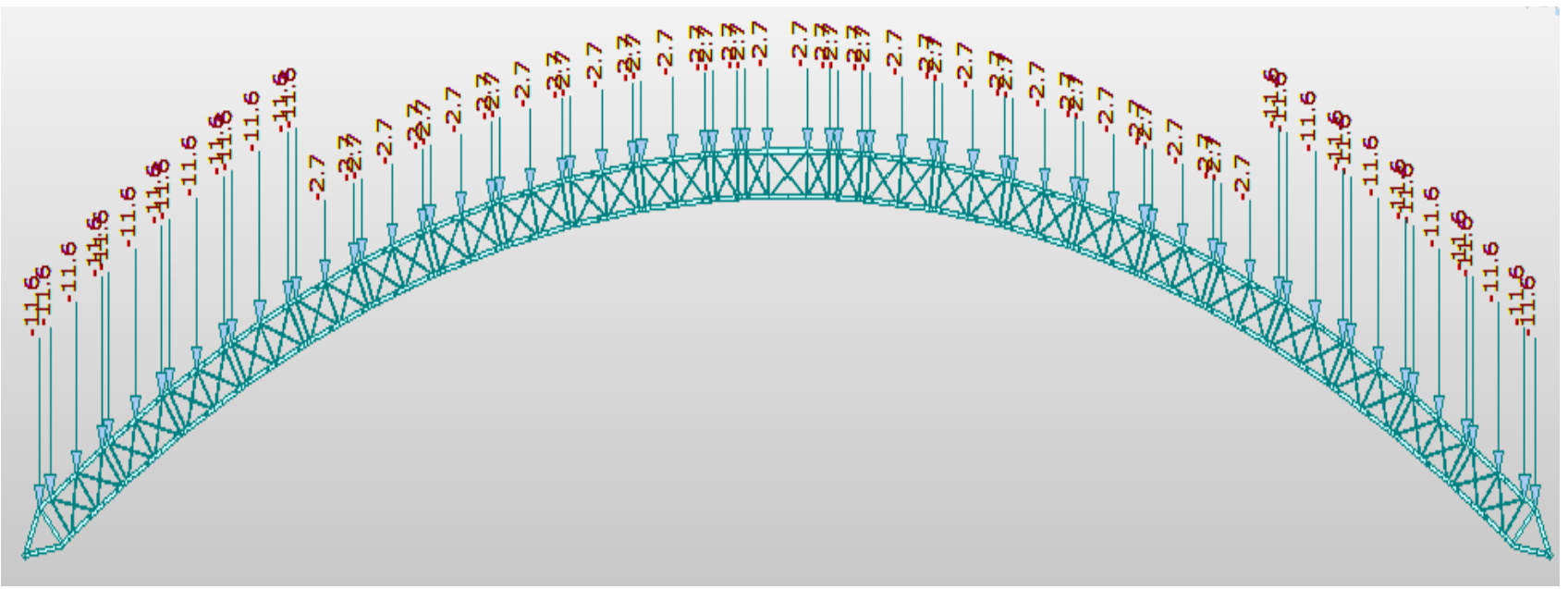

Fig. 6. Model diagram of load application

\section{Results Analysis and Discussion}

\subsection{Influence of the connection method of the upper} chord in the novel arch section

\subsubsection{Comparative analysis of vertical displacement of arch}

Figure 7 shows the vertical displacement of the arch at $\mathrm{L} / 2$ and L/4. Figure 7 shows that when the rigid connection is used in the upper chord of the novel arch, the deformation during casting of each ring is smaller than that of the previous construction stage, and the vertical displacement at $\mathrm{L} / 4$ is small. The maximum deformation occurs in the vault casting, where the maximum vertical displacement changes are $31.0,21.4$, and $30.9 \mathrm{~mm}$ for the three stages. In the case of hinge connection of the upper chord, the vault deformation is largest when casting the baseplate arch vault section, and the maximum vertical displacement compared with the previous construction stage is $122.9 \mathrm{~mm}$. The arch vault deformation is largest when casting the web arch waist section of the ring, and the maximum vertical displacement change compared with the previous construction stage is 
$223.2 \mathrm{~mm}$. When the arch vault is cast, the vault deformation is the largest and the maximum vertical displacement is $323.4 \mathrm{~mm}$. Maximum displacement may occur at different construction stages, but the deformation trends of the three construction stages of each ring are similar.

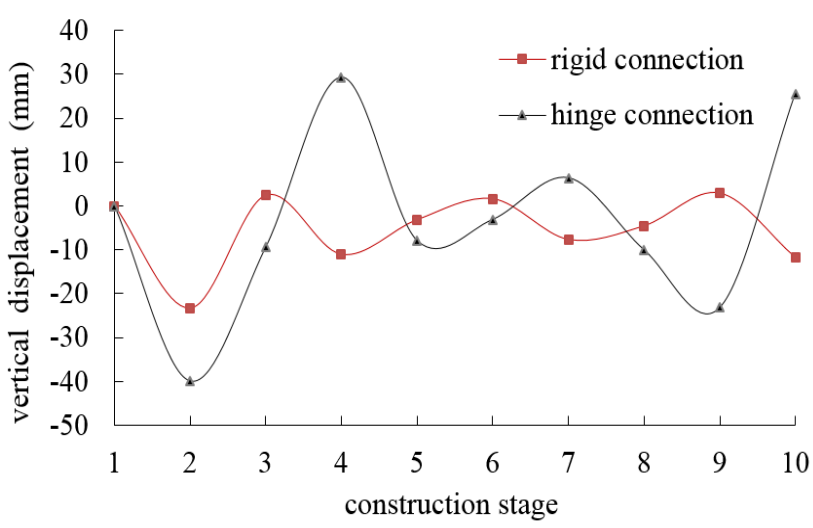

(a) Vertical displacement at $\mathrm{L} / 4$

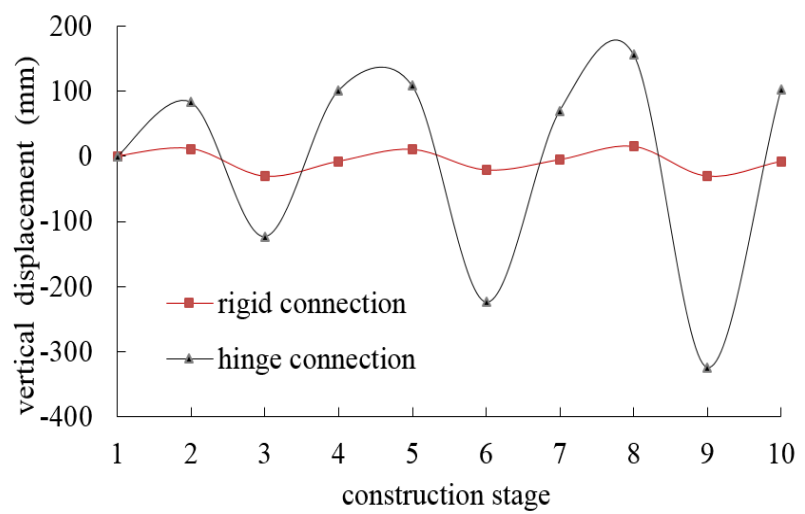

(b) Vertical displacement at $\mathrm{L} / 2$

Fig. 7. Vertical displacement of the arch at each stage

Based on the linear arch shape in the cast-in-place process, the vertical displacement of each of its sections and the linear influence is small in the case of a rigid connection. When a hinge connection is adopted in the upper chord, the vertical displacement of each section changes substantially, and the linear influence on the arch ring is obvious.

\subsubsection{Comparative analysis of stress on the arch}

Figure 8 shows the maximum stresses on the upper chords of the arch foot, standard, and the vault sections of the novel arch, which are the stresses of the same chords in different construction stages.

Comparative analysis of the data in Figure 8 shows that a rigid connection is adopted for the upper chord of the novel arch. In addition, the stress on the upper chord of the arch and the standard sections is smaller than that in the case of hinge connection, and the stress increment per stage is small. After the vault ring is cast, the stress on the upper chord meets the allowable compressive stress of the steel structure but considerably increased for the hinge connection of the upper chord. After the top plate is cast, stress is greater than the threshold and changes substantially compared with the previous construction stage.

Compared with hinge connection, a rigid connection of the upper chords exhibits smaller vertical displacement, stress, and stress increment. In addition, less linear influence occurs on the arch ring. Therefore, a rigid connection is applicable to the upper chords.

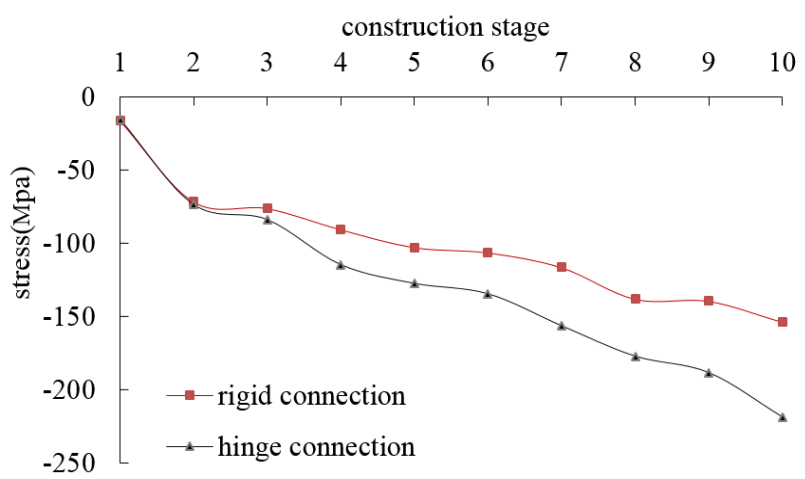

(a) Stress diagram on the upper chord of the arch foot section

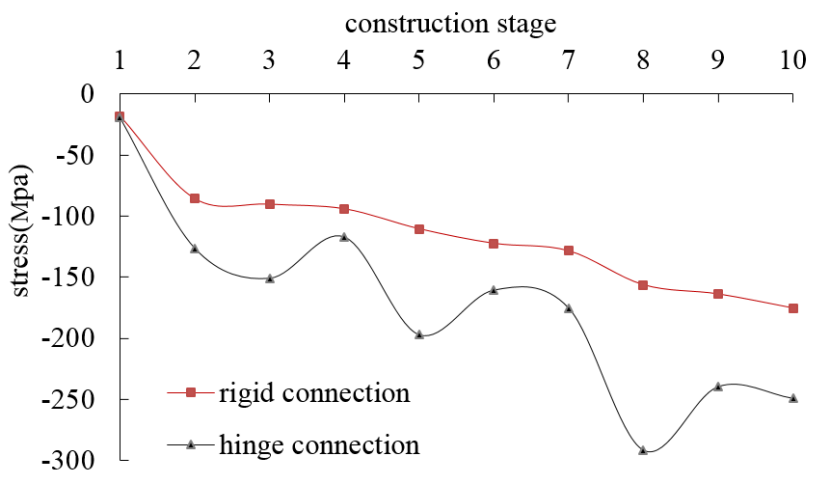

(b) Stress diagram on the upper chord of the standard section

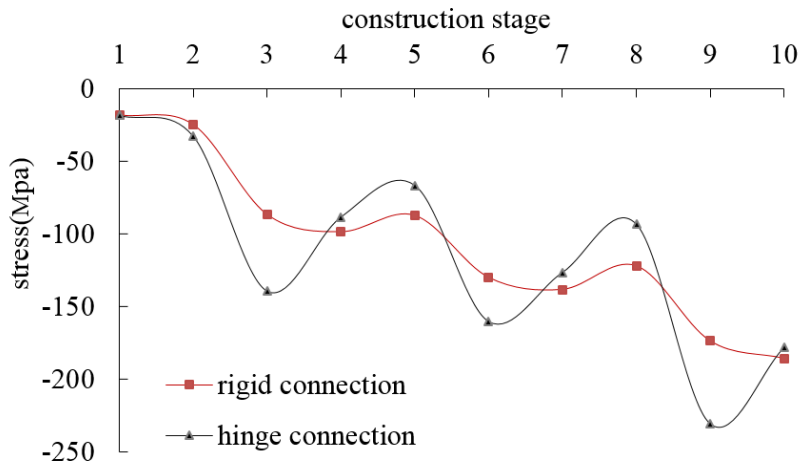

(c)Stress diagram on the upper chord of the vault section Fig. 8. Stress diagram on the chord of the arch at each stage

\subsection{Influence of arch foot boundary conditions on the novel arch}

\subsubsection{Comparative analysis of vertical displacement of the arch}

Table 1 shows the vertical displacement of each arch section. Table 1 shows that when a two-hinged arch is at the boundary of the arch foot, the deformation during the construction of the arch ring is less than that of the previous construction stage. In addition, the vertical displacement at L/4 changes slightly. Maximum deformation occurs during the casting of the vault section. The maximum vertical displacement changes are 31.0, 21.4, and $30.9 \mathrm{~mm}$, respectively. As for the no-hinge arch, the maximum deformation during the construction of the arch ring occurs in the casting of the arch vault section, with the largest at the arch vault. The maximum vertical displacement changes are $30.6,21.2$, and $30.0 \mathrm{~mm}$, respectively. By analyzing the 
Wusi Chen, Yonggao Tan, Peng Xiong, Peng Duan, Wang Yang and Jingyuan Wang/

Journal of Engineering Science and Technology Review 12 (6) (2019) 34 - 43

vertical deformation of each section of the no-hinge or twohinge arches, the corresponding vertical displacement is basically the same. When the boundary condition of the arch is no-hinge or two-hinge, no influence is obvious on the arch deformation.

Table 1. Vertical displacement of the arch at each stage (mm)

\begin{tabular}{c|c|c|c|c|c|c|c|c|c|c|c|c|c|c|c|c|c|c|}
\hline \multicolumn{2}{c|}{ Construction stage } & $\mathbf{1}$ & $\mathbf{2}$ & $\mathbf{3}$ & $\mathbf{4}$ & $\mathbf{5}$ & $\mathbf{6}$ & $\mathbf{7}$ & $\mathbf{8}$ & $\mathbf{9}$ & $\mathbf{1 0}$ \\
\hline \multirow{2}{*}{$\mathrm{L} / 4$} & Two-hinge & 0.0 & -23.4 & 2.4 & -11.1 & -3.2 & 1.6 & -7.7 & -4.6 & 2.9 & -11.8 \\
& No-hinge & 0.0 & -23.2 & 2.3 & -11.1 & -3.1 & 1.6 & -7.8 & -4.5 & 2.7 & -11.7 \\
\hline \multirow{2}{*}{$\mathrm{L} / 2$} & Two-hinged & 0.0 & 11.5 & -31.0 & -8.1 & 10.2 & -21.4 & -5.6 & 14.8 & -30.9 & -8.2 \\
& No-hinge & 0.0 & 12.3 & -30.6 & -8.0 & 9.9 & -21.2 & -5.6 & 14.3 & -30.5 & -8.1 \\
\hline
\end{tabular}

\subsubsection{Comparative analysis of the arch stress}

Analyzing the data in Figure 9, in the case of different boundary conditions of the novel arch, the maximum stresses of the upper chord of the standard and vault sections are similar. The upper and lower chords of the arch are influenced to a certain extent. As for two-hinged boundary condition of the arch foot, the stress on the chord of the arch foot section is less than that when the boundary condition is no-hinge.

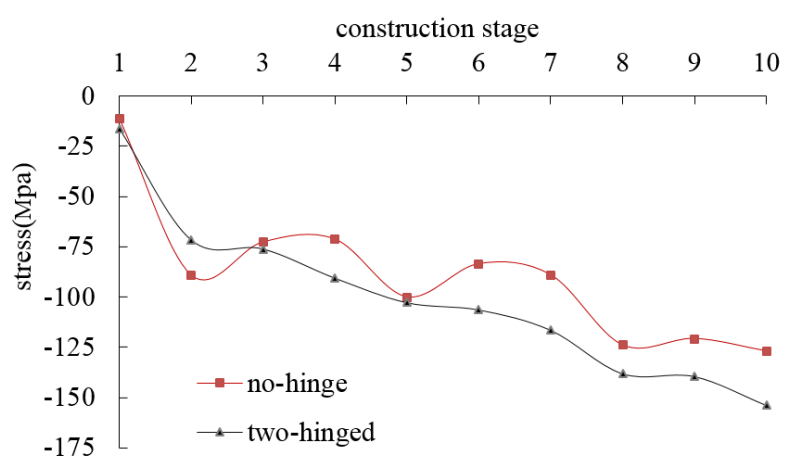

(a) Comparison diagram of stresses on the upper chord

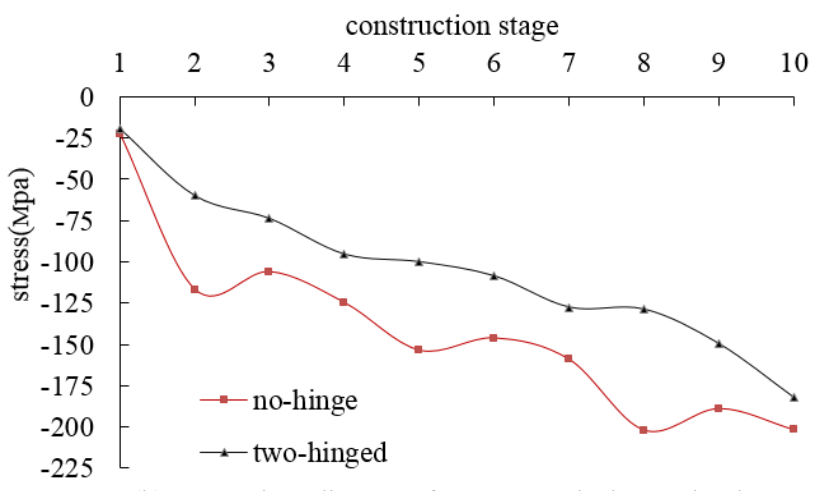

(b) Comparison diagram of stresses on the lower chord Fig. 9. Comparison of stresses on the chord of the arch foot section

Figure 10 shows the axial force of the upper and lower chords of the arch section. Comparative analysis of the data in Figure 10 shows that the change trend of the axial force of the upper and lower chords of the no-hinge and two-hinge arch foot sections is the same. For the two-hinged arch, the axial force of the chord is greater than the stress on the upper chord of the no-hinge arch at each construction stage. The maximum axial force of the two-hinge arch is $951.7 \mathrm{KN}$ and that of the lower chord of the no-hinge arch is $1076.5 \mathrm{KN}$.

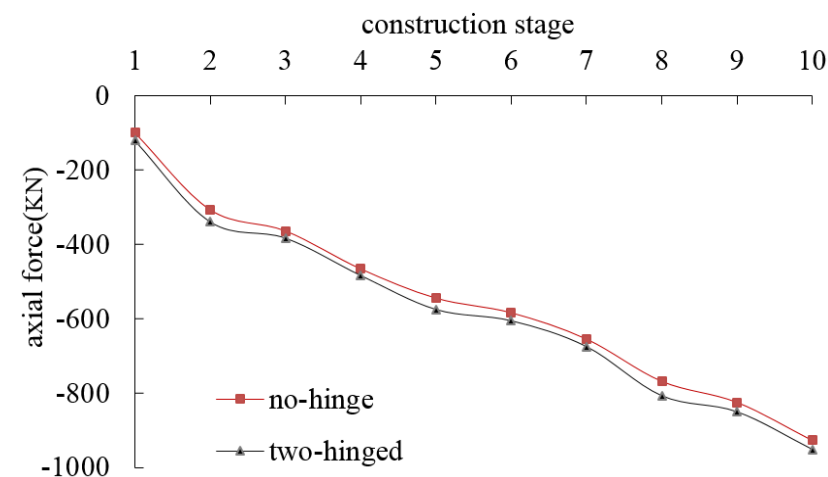

(a) Comparison of the axial force of the upper chord

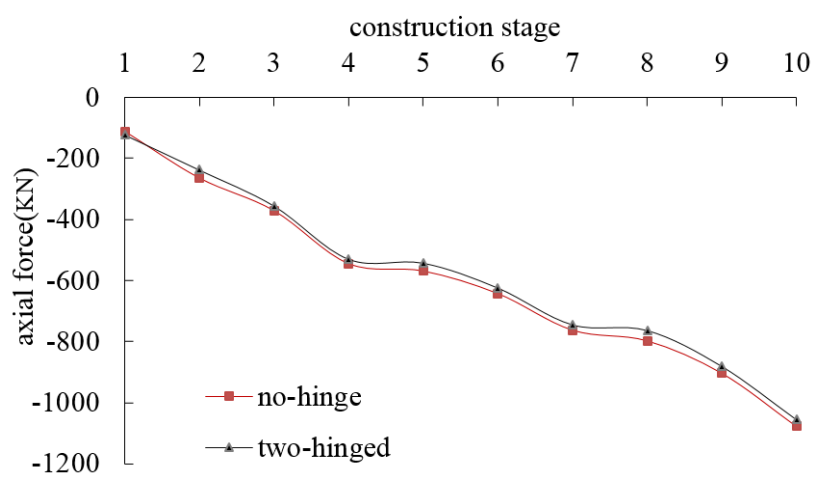

(b) Comparison of the axial force of the lower chord

Fig. 10. Comparison of the axial force of the chord of the arch foot section

When the same load is applied to the arch, the safety factors of stress and axial force of the two-hinged arch are stronger and can withstand greater loads. Therefore, the twohinged arch is the optimal boundary condition.

\subsection{Influence of temperature changes on the arch}

\subsubsection{Calculation and analysis of temperature changes on the arch}

Figure 11 shows the deformation results. Figure 11 shows that the deformation caused by uniform temperature increase has little influence on the deformation of the arch foot section while that of the vault section is large. When the temperature uniformly increases by $20{ }^{\circ} \mathrm{C}$, the vault deformation rises by $17.9 \mathrm{~mm}$. As the temperature decreases by $20^{\circ} \mathrm{C}$, the vault deformation declines by $16.3 \mathrm{~mm}$. 


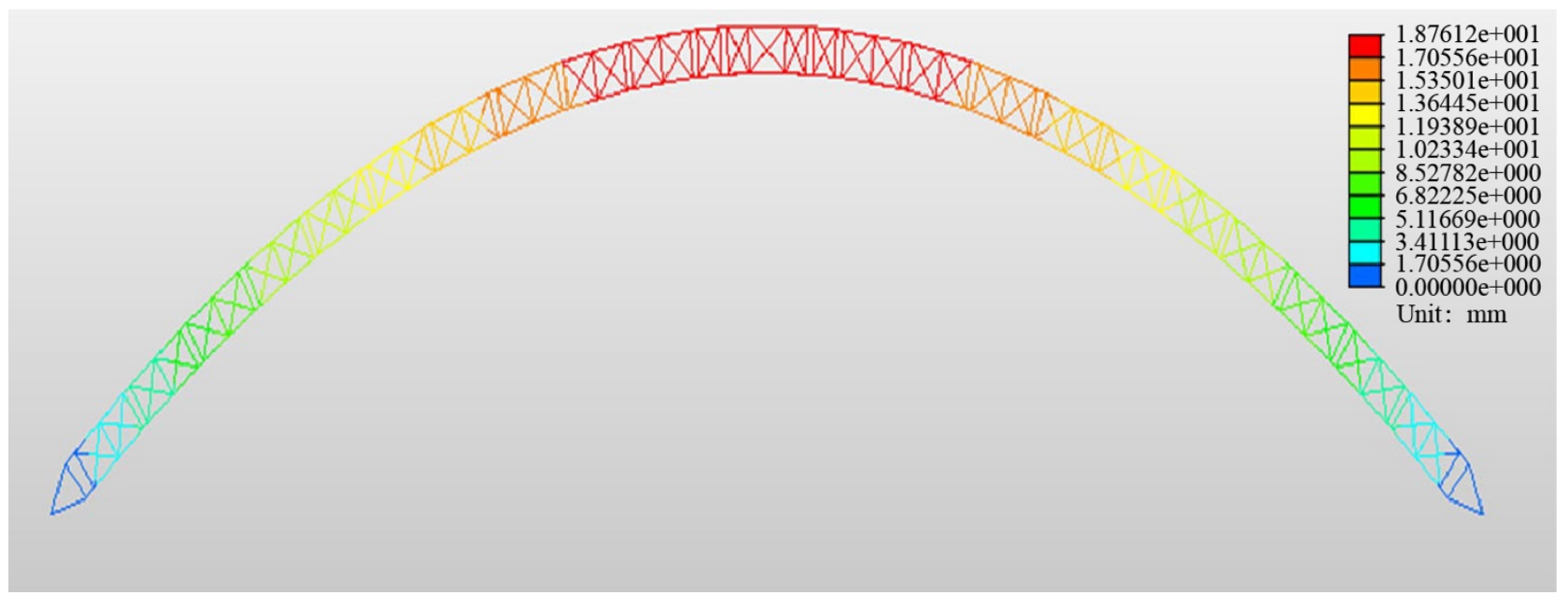

(a) Temperature rises by $20^{\circ} \mathrm{C}$

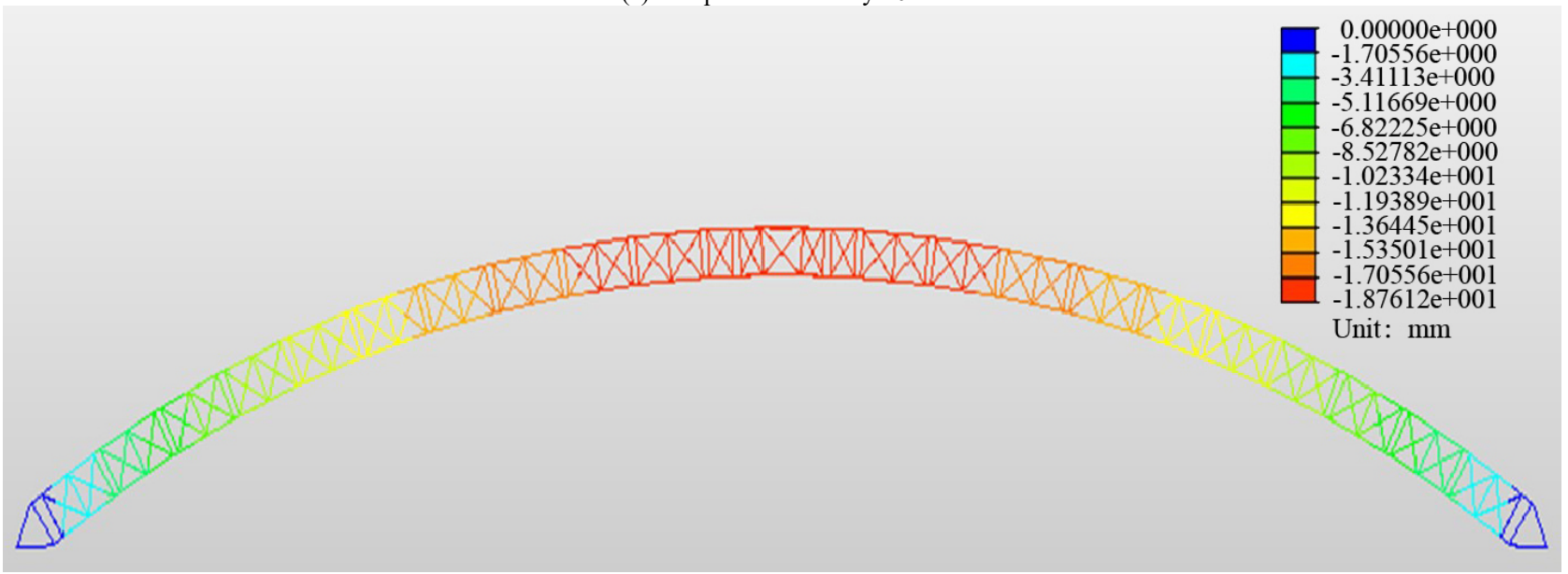

(b) Temperature declines by $20^{\circ} \mathrm{C}$

Fig. 11. Influence of arch temperature on deformation

Figure 12 shows the stress results. Figure 12 shows that the uniform temperature increase has little influence on the compressive and tensile stresses in the standard and vault sections. The stress on the standard section is small as the temperate uniformly declines, but the compressive stress on the vault section is approximately 10.0 MPa. When the temperature rises or declines uniformly, the compressive stress on the arch foot section becomes greater than 10.0 $\mathrm{MPa}$. The tensile stress changes more obviously compared with the previous two sections. Therefore, the influence of temperature in the arch foot section should be considered.

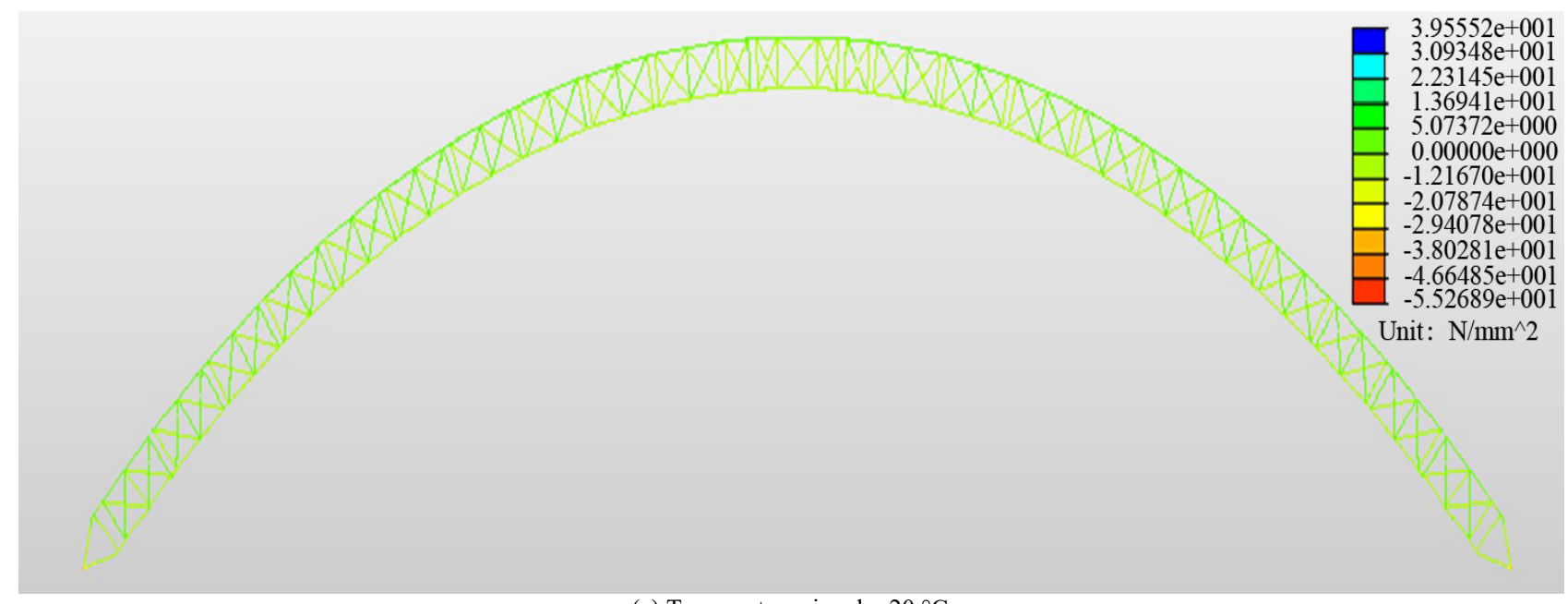

(a) Temperature rises by $20{ }^{\circ} \mathrm{C}$ 


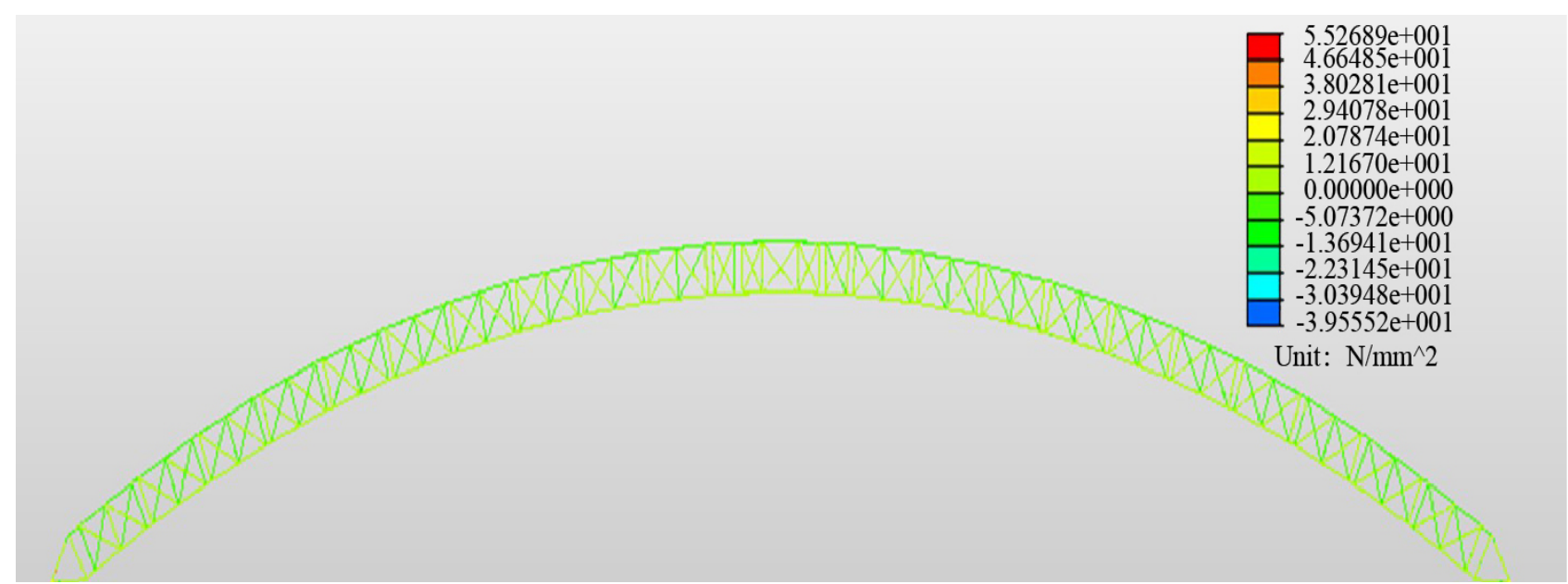

Fig. 12. Influence of temperature of the arch on stress

(b) Temperature declines by $20^{\circ} \mathrm{C}$

4.3.2 Comparative analysis of temperature changes of the arch

Data analysis from Figure 13 reveals that the vertical displacement of the arch foot refers to the numerical displacement at the joint between the arch foot and the first standard sections. In addition, the change value of the vertical displacement in each section is the numerical displacement increment at normal temperature. The deformation at the arch foot at uniform temperature is negligible, but the vertical displacement at the vault is large. Therefore, considering the influence of temperature in the casting of the arch ring is necessary.

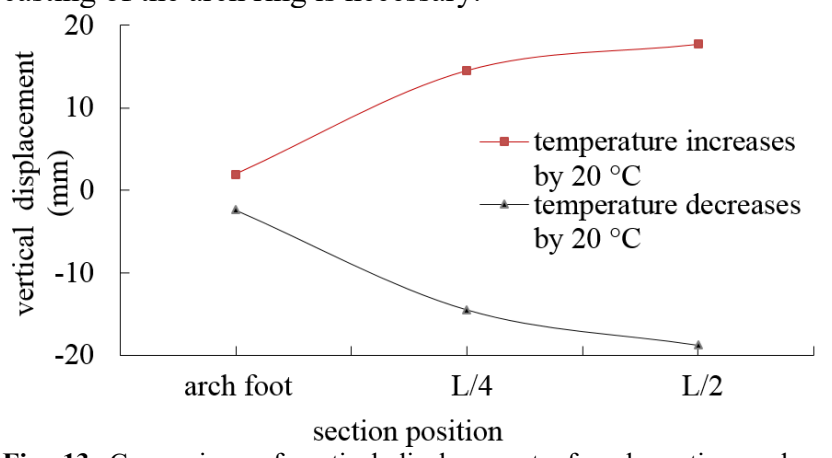

Fig. 13 Comparison of vertical displacement of each section under different conditions

Given that the influence on the upper and lower chords is almost the same at uniform temperature, Figures 14-16 show the compressive stress of the upper chord and the tensile stress of the vertical web member.

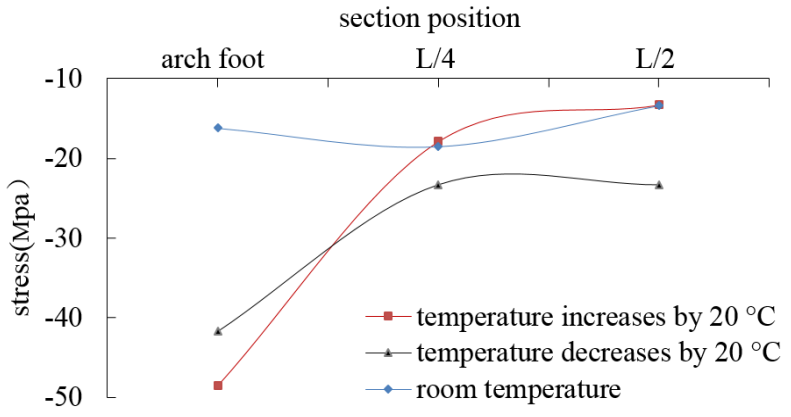

Fig. 14. Comparison of stresses on the upper chord at different temperatures

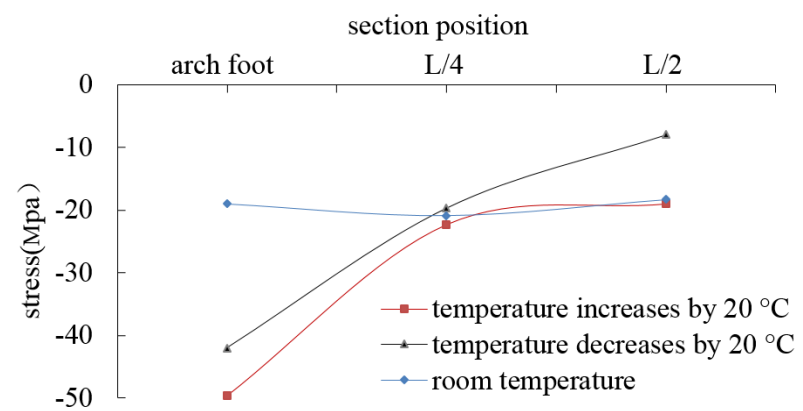

Fig. 15. Comparison of stresses on the lower chord at different temperatures

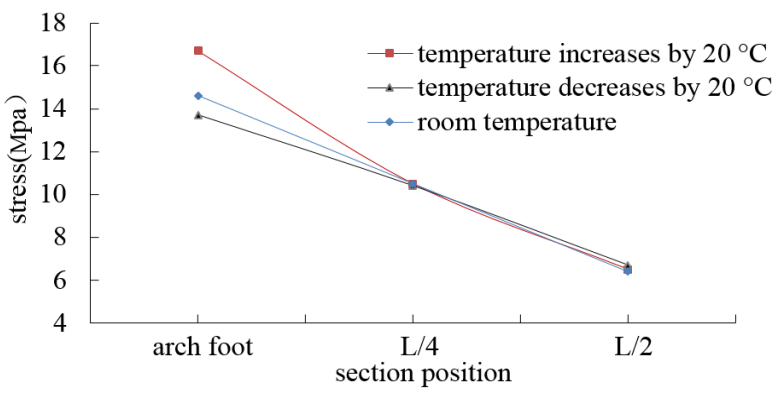

Fig. 16. Comparison of stress on the vertical web member at different temperatures

Data analysis from Figures 14-16 reveals that uniform temperature increases and decreases cause similar stress change trends in each section, and temperature change clearly influences the arch foot section. The stress changes at $\mathrm{L} / 4$ and $\mathrm{L} / 2$ of the arch caused by the uniform $20{ }^{\circ} \mathrm{C}$ temperature increases are negligible, but the uniform temperature decreases leads to obvious stress changes at L/4 and $\mathrm{L} / 2$. Therefore, the influence of temperature on the arch, especially the arch section, requires consideration in construction calculation. Given that the uniform temperature drop clearly influences the stress of the arch, appropriate arch closing temperature should be determined for both assembly and concrete casting.

\subsection{Analysis of the arch stability}

\subsubsection{Influence of different spans on the stability of the} novel arch

In the reconstruction bridge project in Yichang, China, the arch bridge has a span of $90 \mathrm{~m}$ and an arch ring width of 7.5 
$\mathrm{m}$. The novel arch bridge with adjustable axis is $8.3 \mathrm{~m}$ long, and composed of five standard sections and four sets of connection systems. Therefore, the width is $8.3 \mathrm{~m}$ when the model is used to analyze the effect of different spans on the arch stability. The stability of the novel arch with different span diameters of 60,90 , and $120 \mathrm{~m}$ is analyzed. Figure 17 shows the comparison of the fourth-order instability load coefficients of the arch with different spans.

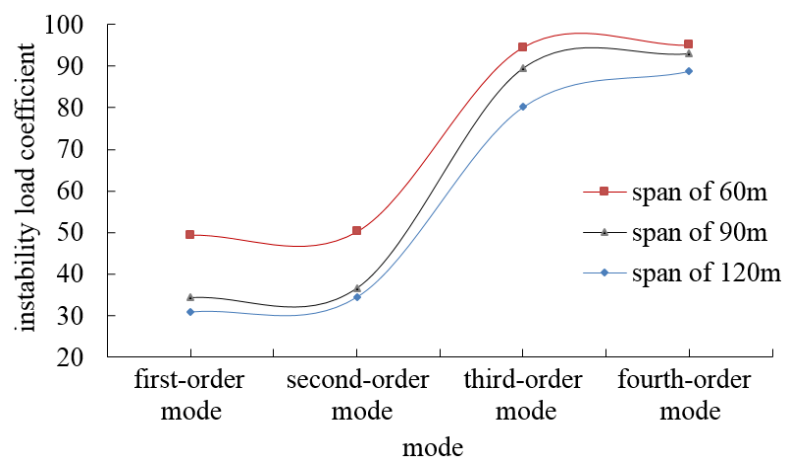

Fig. 17. Comparison of the fourth-order instability load coefficients of the arch with different spans

Figure 17 shows that the load coefficients of the firstand second-order modes and those of the third- and fourthorder modes are close under the arching condition. The load coefficient under the span of $60 \mathrm{~m}$ is greater than that under the spans of 90 and $120 \mathrm{~m}$. Therefore, under the same width condition, the stability of the novel arch is lower as the span increases.

\subsubsection{Influence of width the stability of the novel arch} Based on the span of $90 \mathrm{~m}$, the stability of the novel arch models with varying widths of $4.5,6.4,8.3$, and $10.2 \mathrm{~m}$ is analyzed. Figure 18 compares the fourth-order instability load coefficients of the arch with varying widths.

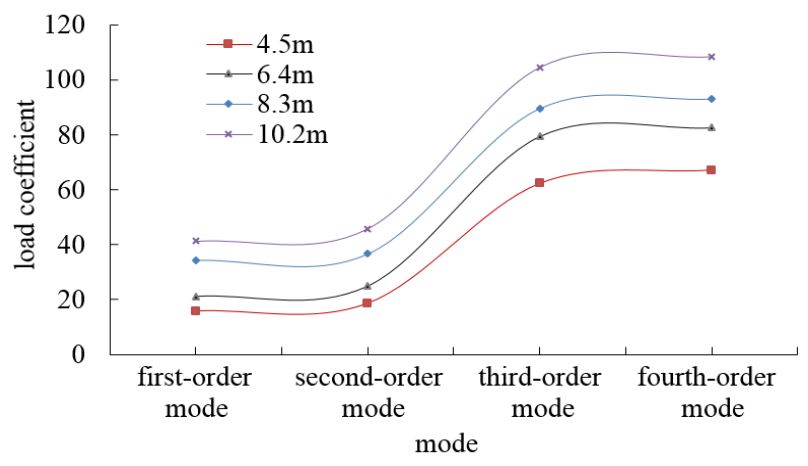

Fig. 18. Comparison of the four-order instability load coefficients of the arch with varying widths

Figure 18 shows that in the arching condition, the load coefficient and stability of the novel arch are enhanced as the width of the arch increases. Without considering wind load, the minimum width-to-span ratio applicable to the 90 m-wide arch is 1:20.

\section{Conclusion}

To clarify the mechanical response characteristics of the novel steel arch with adjustable axis, this study used Midas Civil to establish a finite element analysis model. The sensitivity factors that affect the mechanical deformation characteristics, such as the connection method of the upper chords in the arch section, boundary condition of the arch foot hinge, and temperature, were analyzed. Furthermore, the influence of span and width on the arch stability was discussed. The following conclusions could be drawn:

(1) Compared with hinge connection, the vertical displacement of each section is smaller in the case of rigid connection, the stress and its increments are smaller, and less linear influence occurs on the arch ring. Therefore, a rigid connection is suitable for the upper chords of the arch section.

(2) Compared with the no-hinge form, the arch hinge has greater safety factors of stress and axial force in the twohinge form and can withstand larger loads. Therefore, the two-hinge structure system applies to the arch.

(3) Temperature rise and decline show clear influence on the arch deformation. Temperature drop influences the stress of the arch more significantly.

(4) Under the same width, the span is negatively correlated with the stability of the novel arch. Under the same span, the width is positively correlated with the stability of the novel arch. Regardless of the wind load, the minimum width-to-span ratio suitable for the arch reaches $1: 20$.

In this study, the mechanical sensitivity factors and stability of the novel steel arch with adjustable axis were analyzed. The connection modes of upper chords of the steel arch, boundary conditions of different arch foot hinges, and the mechanical response characteristics of the arch at different temperatures were explored. Moreover, the influence of span and width on the arch stability was discussed. The results can provide reference for the subsequent development of the novel steel arch. However, the adjustment bolts of the upper chord of the arch section were simplified in the model calculation. Therefore, future studies should refine and modify the adjustment bolts of the upper chord of the arch section to further study the mechanical behavior characteristics of the novel steel arch.

\section{Acknowledgements}

This work was supported by the Science and Technology Research Program of Chongqing Municipal Education Commission (Grant No.KJQN201904310) and the Science and Technology Project of Hubei Highway Administration Bureau (Key Technology of Cast-in-place Reinforced Concrete Arch Bridge based on Adjustable Steel Arch[KJ2019003]).

This is an Open Access article distributed under the terms of the Creative Commons Attribution License

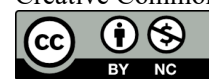

\section{References}

1. Zheng L Q, "Steel Arch Construction of Box Arch Ring Stress Analysis and Stability Study". Master thesis of Chang'an University, China, 2016, pp.6-10.
2. Liu C B, "Analysis on Special Steel Arches for Bridges in Southwest China". Construction Science and Technology, 2015(10), 2015, pp. 159-160. 
Wusi Chen, Yonggao Tan, Peng Xiong, Peng Duan, Wang Yang and Jingyuan Wang/

Journal of Engineering Science and Technology Review 12 (6) (2019) 34 - 43

3. Zhang J J, Zhang Y Q, Li C X, Peng B H, "Stress Analysis of Steel Arch Based on the Combination of Arch and Arch Ring". Highway \& Automotive Applications, 2016(03), 2016, pp. 165-168.

4. Zhang L Y, Cheng J, Yang J J, Yu X M, "Research on the Iterative Algorithm of Naked Arch Layout and Value of Pre-raise Arches". Technology of Highway and Transport, 2014(03), 2014, pp. 54-58.

5. Philip S. Halding, Kristian D. Hertz,Jacob W. Schmidt, et al, "Fullscale load tests of Pearl-Chain arches". Engineering Structures, 131, 2017, pp. 101-114.

6. Qiu T T, Chen W D, Li X J, "Comparative Analysis of Stress Performance of "321" Type Bailey Beam with Deck Type and Bearing Type". Shanxi Architecture, 43(22), 2017, pp. 43-45.

7. Tang Y X, "Standing-type Steel Arch Construction Design and Stress Analysis". Western China Communication Science and Technology, 2016(7), 2016, pp. 27-30.

8. Zhang Y P, Peng B H, Li C X, et al., "Reasonable Construction Procedures and Methods for the Overall Unloading of Steel Arches". Journal of China \& Foreign Highway, 37(1), 2017, pp. 68-72.

9. Zanardo G, Pellegrino C, Bobisut C, et al., "Performance evaluation of short span reinforced concrete arch bridges". Journal of bridge engineering, 9(5), 2004, pp. 424-434.

10. Wang Y, Zhan Y, Zhao R, "Analysis of thermal behavior on concrete box-girder arch bridges under convection and solar radiation". Advances in Structural Engineering, 19(7), 2016, pp. 1043-1059.

11. Elrehim M Z A, Eid M A, Sayed M G, "Structural optimization of concrete arch bridges using Genetic Algorithms". Ain Shams Engineering Journal, 10(3), 2019, pp. 507-516.

12. Dagher H J, Bannon D J, Davids W G, et al., "Bending behavior of concrete-filled tubular FRP arches for bridge structures". Construction and Building Materials, 37, 2012, pp. 432-439.

13. Hamed E, Chang Z T, Rabinovitch O, "Strengthening of reinforced concrete arches with externally bonded composite materials: Testing and analysis". Journal of Composites for Construction, 19(1), 2014, pp. 159-160.
14. Salonga J, Gauvreau P, "Comparative study of the proportions, form, and efficiency of concrete arch bridges". Journal of Bridge Engineering, 19(3), 2013, pp. 45-51.

15. Khan E, Sullivan T J, Kowalsky M J, "Direct displacement-based seismic design of reinforced concrete arch bridges". Journal of Bridge Engineering, 19(1), 2013, pp. 44-58.

16. Jiang X, "Study on the Stability of Steel Arch in Construction". Master thesis of Chongqing Jiaotong University, China, 2014, pp.2327.

17. Tang L F, "Discussion on Test methods of Bridge Support Load". Journal of Highway and Transportation Research and Development, 9(5), 2017, pp. 149-151.

18. Y Wang, AP Thrall, TP Zoli, “Adjustable module for variable depth steel arch bridges". Journal of Constructional Steel Research, 2016(126), 2016, pp. 163-173.

19. Jiang T Y, Luo Z W, Jiang M F, "Pre-compression Test and Precamber Setting of Steel Arch Water Tank". Highway, 41(1), 2015, pp. $127-130$

20. Zhang Y P, Peng B H, Li C X, et al., "Reasonable Construction Procedures and Methods for the Overall Unloading of Steel Arches". Journal of China \& Foreign Highway, 37(1), 2017, pp. 68-72.

21. Ma F, Zhang L B, "Design and Application of Steel Arch Frame in Concrete Box Arch Bridge". Journal of China \& Foreign Highway, 36(3), 2016, pp. 173-176.

22. Zhao J G, Jiang G, Du B, "Stochastic and Sensitivity Analysis about Construction Deflection of Adjustable Steel Arch Centering". Building Structure, 47(s1), 2017, pp. 1180-1184.

23. Zhao W, Yang S J, Zhang Y B, "Technology of Horizontal Span Steel Arch Traverse Construction”. Highway, 2017(12), 2017, pp. 166-169.

24. Zhong W, Xiao Y J, "Analysis of Stability and Bearing Capacity of Aqueduct Bailey Steel Arch”. Technology of Highway and Transport, 2014(04), 2014, pp. 89-91.

25. Yuan P, “Adjustable Type Steel Arch Stability Analysis and Construction Process Control". Master thesis of Changsha University of Science \& Technology, China, 2018, pp.35-37. 